\title{
Application of Nanomaterials in Brain Cancers Diagnosis and Treatment: A Mini-Review
}

\author{
Ghazale Molaverdi ${ }^{1}$, Tahmineh Rajabi*2 and Fereshte Molaverdi ${ }^{2}$ \\ ${ }^{1}$ Student Research Committee, Alborz University of Medical Science, Iran \\ ${ }^{2}$ Department of Materials Engineering, Tarbiat Modares University, Iran \\ *Corresponding author: Tahmineh Rajabi, Department of Materials Engineering, Tarbiat Modares University, Tehran, Iran, Tel: (+98) \\ 9398747888, Fax: 88005040, Email: tahmine.rajabi1997@gmail.com \\ To Cite This Article: Ghazale Molaverdi, Tahmineh Rajabi, Fereshte Molaverdi. Application of Nanomaterials in Brain Cancers Diagnosis and \\ Treatment: A Mini-Review. 2020 - 11(1). AJBSR.MS.ID.001591. DOI: 10.34297/AJBSR.2020.11.001591.
}

Received: 眥 November 03, 2020; Published: 眥 November 30, 2020

\begin{abstract}
One of the foremost difficult problems in oncology is the treatment of brain cancers. Within the last decades, nanotechnology has been utilized to perform a new diagnostic approach and therapeutic drug delivery systems in brain tumors. Using nanoparticles allows better brain tumor visualization, characterization, and delineation. The central focus of this review is that the diagnostic and therapeutic effects of nanoscale materials on brain tumors.
\end{abstract}

Keywords: Brain cancer, Drug delivery, Brain tumor targeting, Nanoparticles, Biomaterials, Glioma, Diagnosis, Treatment

\section{Introduction}

Nowadays over 100 brain tumor types were classified according to genetics, clinical manifestations, histopathological features, and invasion [1]. The universal average cancer incidence of brain tumor was documented 3.4 per 100,000 individuals in 2017 and generally, daily approximately 700 individuals are diagnosed with a brain tumor [2]. Brain tumors often bear a poor prognosis for patients [3]. Malignant brain tumors entail primary brain tumors, originated from brain tissues or brain surrounding tissues, like malignant gliomas, and metastatic brain tumors from peripheral cancers, like melanoma, lung, colon, and breast cancers. It is estimated $10 \%$ to $20 \%$ of patients with peripheral cancer develop brain metastases [1]. glioma, the foremost common primary brain tumor [4], accounting for $78 \%$ of all malignant brain tumors raises a special challenge over difficulties of detecting it in early stages and also the proximity of anatomical structures essential for several important functions. Gliomas impose a significant clinical problem because of their high prevalence and invasive phenotype giving rise to exceedingly poor prognosis [5]. The foremost common and aggressive kind of high-grade glioma is Glioblastoma multiforme (GBM) [4] which continues to be a formidable challenge. The prognosis for patients with GBM is extremely poor with a median survival of 15 months. GBM is acknowledged by diffuse infiltration, genomic instability, necrosis, drug resistance, and therefore the absence of effective drug delivery strategies has posed the challenge of not making progress in its treatment over the last decades $[6,7]$. Imaging and diagnosis of cancer at an early stage, multifunctional targeting systems, ability to the detection of molecular change, and prevention of transformation of pro-cancer cells into cancer cells, are achieved by using nanotechnology [8]. Differing types of small ligands can attach to nanoparticles and deliver to the brain tumors [9]. The coating of nanoparticles with transmembrane peptides or antibodies leads to recognizing the receptors in tumors. Nanomaterials applied in brain tumor diagnosis and treatment might be divided into organic-based, inorganic-based, and composite nanoparticles based on materials [10].

\section{Nanomaterials Within the Diagnosis of Brain Tumors}

Although the leading imaging techniques for brain tumors like computed tomography (CT), positron emission tomography (PET), and magnetic resonance imaging (MRI) are advantageous, assessments of cancer classification, histological type, grade and aggressiveness, and determination of the therapeutic approach require invasive biopsy. Furthermore, for some brain tumors, 
determining the tumor size is difficult because the edema around the tumor does not easily provide accurate discrimination of tumor margins. Although the employment of contrast agents may help to overcome this fault and provide tumor margins estimation from the largest cross-sectional area, the efficacious use of contrast agents is feasible only in people with a compromised blood-brain barrier (BBB) [5]. The rationale for this issue is that classical contrast agents don't usually pass through the intact BBB because of their

Table 1: Diagnostic application of nanomaterials in brain tumors. high molecular weight, so the conjugation with nanomaterials like magnetic nanoparticles able to cross the barrier and yield more advantages as increased contrast sensitivity and binding affinity seems to be a solution. [2]. Multifunctional nanoparticles may result in beneficial gains in brain tumors diagnosis and management [2]. Applications of nanoscale materials within the diagnosis of brain cancers are summarized in Table1.

\begin{tabular}{|c|c|c|c|}
\hline Application & Nanomaterial & Advantages & Reference \\
\hline \multirow[b]{2}{*}{ Imaging probes in MRI } & Gadolinium NPs & $\begin{array}{l}\text { Enhance MRI contrast for mostly T1-weighted } \\
\text { images, which give contrast enhancement for } \\
\text { tissues with high-fat content }\end{array}$ & {$[10,12]$} \\
\hline & $\begin{array}{l}\text { Superparamagnetic iron oxide NPs } \\
\text { (SPIO) }\end{array}$ & $\begin{array}{l}\text { Magnetic control of targeting, Enhance MRI } \\
\text { contrast for mostly T2-weighted images, which } \\
\text { provides contrast enhancement for tissues with } \\
\text { high water content }\end{array}$ & \\
\hline $\begin{array}{c}\text { Surface-enhanced resonance } \\
\text { Raman scattering (SERRS) and CT } \\
\text { imaging }\end{array}$ & $\mathrm{Au}$ NPs & $\begin{array}{l}\text { Excellent biosafety and easy synthesis methods, } \\
\text { Unique photophysical properties }\end{array}$ & {$[10,11,13]$} \\
\hline \multirow[b]{2}{*}{$\begin{array}{l}\text { Fluorescent nanocarriers (dye- } \\
\text { loaded polymer NPs) }\end{array}$} & Liposome NPs & $\begin{array}{l}\text { High probability of effective drug delivery, } \\
\text { Biocompatible }\end{array}$ & \multirow[b]{2}{*}[10,11,12]{} \\
\hline & $\begin{array}{l}\text { Poly-alkyl-cyano acrylates (PACA), } \\
\text { Poly lctic co glycolic acid (PLGA) }\end{array}$ & $\begin{array}{l}\text { Biodegradable, the introduction of additional } \\
\text { functional building blocks for site-specific delivery, } \\
\text { Multimodal imaging, and Enhanced therapeutic } \\
\text { efficacy }\end{array}$ & \\
\hline Fluorescent NPs & $\begin{array}{l}\text { Quantum dots (QDs), silver } \\
\text { nanoplate cluster }\end{array}$ & $\begin{array}{l}\text { Good solubility in water, High fluorescence } \\
\text { quantum yield, Low fluorescence quenching } \\
\text { rate and Stable chemical properties, Bright, } \\
\text { Photostable }\end{array}$ & {$[10,13]$} \\
\hline Magneto fluorescent NPs & $\begin{array}{l}\text { Zwitterionic magneto fluorescent } \\
\text { NPs (ZW-MFNPs) within the kind } \\
\text { of micelles }\end{array}$ & $\begin{array}{l}\text { Excellent imaging properties and negligible } \\
\text { cytotoxicity }\end{array}$ & ]14[ \\
\hline
\end{tabular}

Note*: MRI: magnetic resonance imaging

NPs: Nano Particles

CT: computed tomography

Au: Gold

\section{Nanomaterials in Treatment of Brain Tumors}

Three main conventional treatments of brain tumors include surgery, radiotherapy, and chemotherapy. Surgery and resection remain the primary and common treatment of most brain tumors, but in some patients, the proximity of the tumor to vital structures like the brain stem or major blood vessels make the surgery impossible. Accordingly, chemotherapy and radiotherapy are the sole treatment options for these cases $[2,5]$.

The least invasive delivery route of chemotherapeutic drugs to the brain is Intravenous injection, but has been limited by several physiological barriers because many anticancer drugs are large hydrophilic molecules [2,7]; moreover, Chemotherapeutic drugs can't distinguish between cancerous cells and healthy cells and they can lead a high systemic side effect on healthy cells and tissues [2]. The brain is protected by a blood-brain barrier (BBB) whose main components include the tight adherence between cerebral endothelial cells (CECs), the efflux pumps, and the metabolic enzymes. BBB separates brain tissue from the bloodstream and limits the influx of molecules from the bloodstream according to their size and hydrophilic characteristics $[11,12]$. The cerebrospinal fluid (CSF) barrier is another barrier that prevents the passage of systemically administrated therapeutic agents. It is created by tightly adhered choroidal epithelial cells that regulate the penetration of the molecules into the interstitial fluid of the brain tissue and prevent most macromolecules from the entrance into the CSF $[13,14]$. Some studies suggest that BBB within the tumor forms another barrier for transporting materials like therapeutic agents. Increased formation of abnormal vessels and angiogenesis result in a blood-brain tumor barrier (BBTB). Unlike BBB in normal brain capillaries, BBTB in tumors is 'leaky', and the tight adherence of endothelial cells within the tumor are compromised; 
nevertheless, The high intratumoral pressure originated from the dysfunctional BBTB limits drug entrance into the tumor from the bloodstream. Furthermore, it is well documented that BBB chiefly remains functional and intact outside of the GBM tumor core, so

Table 2: Diagnostic application of nanomaterials in brain tumors. prevents the passage of therapeutic agents $[3,4,6]$. A new trend in brain cancer therapy is nanotechnology $[15,16]$. Applications of nanomaterials in brain cancer therapy are summarized in Table 2.

\begin{tabular}{|c|c|c|c|c|}
\hline \multicolumn{2}{|c|}{ Nanomaterial } & \multirow{2}{*}{\multicolumn{2}{|c|}{$\begin{array}{l}\text { Advantages } \\
\begin{array}{c}\text { When an external magnetic field is applied, they are active, the ability } \\
\text { to kill cancer cells by hyperthermia }\end{array}\end{array}$}} & \multirow{2}{*}{$\begin{array}{r}\text { Reference } \\
{[13,14]}\end{array}$} \\
\hline \multirow{6}{*}{ Inorganic-based } & Magnetic NPs & & & \\
\hline & Gold & \multicolumn{2}{|c|}{$\begin{array}{l}\text { The ability to cross through the disrupted blood-brain tumor barrier } \\
\text { (for NPs with sizes up to } 50 \mathrm{~nm} \text { ), Easy surface-conjugation with } \\
\text { antibody, Biocompatibility }\end{array}$} & {$[9,11,13]$} \\
\hline & Silica & \multicolumn{2}{|c|}{$\begin{array}{l}\text { Improve the biological performance by conjugation of polymers or } \\
\text { ligands }\end{array}$} & [15] \\
\hline & Silver & \multicolumn{2}{|r|}{ Antibacterial properties } & [13] \\
\hline & $\mathrm{TiO}_{2}$ & \multicolumn{2}{|c|}{$\begin{array}{c}\text { Deactivation of bacteria and viruses, cytotoxicity toward some tumors, } \\
\text { Destruction of brain cancer cells }\end{array}$} & {$[11,16]$} \\
\hline & Carbon nanotubes & \multicolumn{2}{|r|}{ Drug and gene delivery into tumors. } & [9] \\
\hline \multirow[t]{3}{*}{ Organic-based } & Lipid-based & Liposomes & $\begin{array}{l}\text { Biocompatible and biodegradable properties, } \\
\text { their sizes, charges, and compositions will } \\
\text { be easily adjusted to permit for effective } \\
\text { transportation of bioactive molecules, Suitable } \\
\text { for packing neutral, hydrophilic, and hydrophobic } \\
\text { drugs }\end{array}$ & {$[13,15]$} \\
\hline & Polymeric based & Polymeric NPs & $\begin{array}{l}\text { Controlling the drug release profile and } \\
\text { minimizing toxicity during polymer degradation }\end{array}$ & [15] \\
\hline & & Dendrimers & $\begin{array}{c}\text { Slow drug release, High tumor accumulation, Low } \\
\text { polydispersity }\end{array}$ & {$[10,13]$} \\
\hline
\end{tabular}

Note*: NPs: Nanoparticles

\section{Conclusion}

Using nanomaterials has been a new trend for the diagnosis and treatment of brain cancers within the last decades. Based on materials, organic-based and inorganic-based nanoscale materials conjugated with different peptides and ligands can deliver to brain tumors and help to imaging and diagnosis, local release drug and treatment, evaluation in real-time of the effectiveness of a treatment, prevention of cancer with detection of pro-cancer cells. However, more research on their toxicity, biocompatibility, and biodegradability is still needed for clinical applications. Finally, nanotechnology could permit to overcome the BBB and deliver drugs for diagnosis and treatment of brain tumors.

\section{Reference}

1. Garbayo E, Estella Hermoso de Mendoza A, Blanco Prieto MJ (2014) Diagnostic and therapeutic uses of nanomaterials in the brain. Curr Med Chem 21(36): 4100-4131.

2. Bandyopadhyay S K, Roy S (2018) Nanotechnology uses Detection of Brain Tumor-A Review. Global Journal of Nanomedicine 3(4): 555622

3. Cheng Y, Morshed R, Auffinger B, Tobias L, Lesniak M (2014) Multifunctional nanoparticles for brain tumor imaging and therapy. Adv Drug Deliv Rev 66: 42-57.

4. Catalan Figueroa J, Palma Florez S, Alvarez G, Fritz H F, Jara M O, et al. (2016) Nanomedicine and nanotoxicology: the pros and cons for neurodegeneration and brain cancer. Nanomedicine (Lond) 11(2): 171187.
5. Bhojani MS, Van Dort M, Rehemtulla A, Ross B D (2010) Targeted imaging and therapy of brain cancer using theranostic nanoparticles. Mol Pharm $7(6):$ 1921-1929.

6. Seo Y E, Bu T, Saltzman W M (2017) Nanomaterials for convectionenhanced delivery of agents to treat brain tumors. Current Opinion in Biomedical Engineering 4: 1-12.

7. Gregory JV, Kadiyala P, Doherty R, Cadena M, Habeel S, et al. (2019) Systemic Brain Tumor Delivery of Synthetic Protein Nanoparticles for Glioblastoma Therapy. BioRxiv 862581.

8. Demetzos C, Pippa N (2014) Advanced drug delivery nanosystems (aDDnSs): a mini-review. Drug Deliv 21(4): 250-257.

9. Hadjipanayis C G, Bouras A, Chang S (2014) Applications of Multifunctional Nanoparticles in Malignant Brain Tumors. European Association of Neuro-Oncology Magazine 4(1): 9-15.

10. Wu X, Yang H, Yang W, Chen X, Gao J, et al. (2019) Nanoparticle-based diagnostic and therapeutic systems for brain tumors. Journal of Materials Chemistry B 7(31): 4734-4750.

11. Rozhkova E A (2011) Nanoscale Materials for Tackling Brain Cancer: Recent Progress and Outlook. Adv Mater 23(24): 136-150.

12. Meyers J D, Doane T, Burda C, Basilion J P (2013) Nanoparticles for imaging and treating brain cancer. Nanomedicine (Lond) 8(1): 123-143.

13.Zottel A, Videtič Paska A, Jovčevska I (2019) Nanotechnology Meets Oncology: Nanomaterials in Brain Cancer Research, Diagnosis and Therapy. Materials (Basel) 12(10): 1588.

14. Gandhi H, Sharma A K, Mahant S, Kapoor DN (2020) Recent advancements in brain tumor targeting using magnetic nanoparticles. Therapeutic Delivery 11(2): 97-112. 
15. Tsou YH, Zhang XQ, Zhu H, Syed S, Xu X (2017) Drug Delivery to the Brain across the Blood-Brain Barrier Using Nanomaterials. Small 13(43): 1701921.
16. Rozhkova E A, Ulasov I, Lai B, Dimitrijevic N M, Lesniak M S, Rajh, T (2009) A high-performance nanobio photocatalyst for targeted brain cancer therapy. Nano Lett 9(9): 3337-3342. 